\title{
Anthropogenic N Deposition Slows Decay by Favoring Bacterial Metabolism: Insights from Metagenomic Analyses
}

\section{OPEN ACCESS}

Edited by:

Eoin L. Brodie,

Lawrence Berkeley National

Laboratory, USA

Reviewed by:

Kelly Sierra Ramirez,

Netherlands Institute of Ecology,

Netherlands

Adina Howe,

lowa State University, USA

*Correspondence:

Zachary B. Freedman

zacf@umich.edu

${ }^{\dagger}$ Present Address: Lauren C. Cline, College of Biological Sciences,

Saint Paul, MN, USA

Specialty section: This article was submitted to

Terrestrial Microbiology, a section of the journal

Frontiers in Microbiology

Received: 24 December 2015 Accepted: 16 February 2016 Published: 02 March 2016

Citation: Freedman ZB, Upchurch RA, Zak DR and Cline LC (2016) Anthropogenic N Deposition Slows Decay by Favoring Bacterial Metabolism: Insights from Metagenomic Analyses.

Front. Microbiol. 7:259.

doi: $10.3389 /$ fmicb.2016.00259

\author{
Zachary B. Freedman ${ }^{1 *}$, Rima A. Upchurch ${ }^{1}$, Donald R. Zak ${ }^{1,2}$ and Lauren C. Cline ${ }^{1 \dagger}$ \\ 'School of Natural Resources and Environment, University of Michigan, Ann Arbor, MI, USA, ${ }^{2}$ Department of Ecology, \\ Evolution, and Behavior, University of Michigan, Ann Arbor, MI, USA
}

Litter decomposition is an enzymatically-complex process that is mediated by a diverse assemblage of saprophytic microorganisms. It is a globally important biogeochemical process that can be suppressed by anthropogenic $\mathrm{N}$ deposition. In a northern hardwood forest ecosystem located in Michigan, USA, 20 years of experimentally increased atmospheric $\mathrm{N}$ deposition has reduced forest floor decay and increased soil $\mathrm{C}$ storage. Here, we paired extracellular enzyme assays with shotgun metagenomics to assess if anthropogenic $\mathrm{N}$ deposition has altered the functional potential of microbial communities inhabiting decaying forest floor. Experimental $\mathrm{N}$ deposition significantly reduced the activity of extracellular enzymes mediating plant cell wall decay, which occurred concurrently with changes in the relative abundance of metagenomic functional gene pathways mediating the metabolism of carbohydrates, aromatic compounds, as well as microbial respiration. Moreover, experimental $\mathrm{N}$ deposition increased the relative abundance of 50 of the 60 gene pathways, the majority of which were associated with saprotrophic bacteria. Conversely, the relative abundance and composition of fungal genes mediating the metabolism of plant litter was not affected by experimental $\mathrm{N}$ deposition. Future rates of atmospheric $\mathrm{N}$ deposition have favored saprotrophic soil bacteria, whereas the metabolic potential of saprotrophic fungi appears resilient to this agent of environmental change. Results presented here provide evidence that changes in the functional capacity of saprotrophic soil microorganisms mediate how anthropogenic $\mathrm{N}$ deposition increases $\mathrm{C}$ storage in soil.

Keywords: metagenome, saprotroph, $\mathbf{N}$ deposition, $\mathbf{C}$ storage, climate change

\section{INTRODUCTION}

Changes in the composition and function of microbial communities can amplify or moderate anthropogenic modification of global biogeochemical cycles (Falkowski et al., 2008; Zhao et al., 2014). However, our ability to mechanistically link changes in microbial community composition with metabolic responses that control biogeochemical cycles has been limited, especially in regard to the molecular mechanisms slowing plant litter decay under future rates of atmospheric $\mathrm{N}$ deposition (Zak et al., 2008; Liu and Greaver, 2010; Edwards et al., 2011; Eisenlord et al., 2013; Freedman and Zak, 2014). By the end of this century, terrestrial ecosystems in the eastern United 
States and Europe will receive quantities of anthropogenic nitrogen $(\mathrm{N})$ that are unprecedented over the history of life on Earth (Galloway et al., 2004; Torseth et al., 2012). This aspect of global change has the potential to constrain the accumulation of anthropogenic $\mathrm{CO}_{2}$ in the Earth's atmosphere (Magnani et al., 2007; Zak et al., 2008), and therefore, slow the pace of climate warming. For 20 years, we have conducted a long-term field experiment that simulates future rates of anthropogenic $\mathrm{N}$ deposition to understand microbial processes mediating ecosystem $\mathrm{C}$ storage. Our experiment has revealed that future rates of anthropogenic $\mathrm{N}$ deposition have reduced microbial decay, which substantially increased organic matter accumulation in forest floor $(+51 \%)$ and surface mineral soil ( $+18 \%$; Zak et al., 2008). These biochemical responses have occurred in parallel with a change in the composition of saprotrophic fungi and bacteria inhabiting soil, as well as changes in the prominence of fungal and bacterial lignocellulose metabolism (Eisenlord and Zak, 2010; Edwards et al., 2011; Eisenlord et al., 2013; Freedman and Zak, 2014). Nonetheless, we do not understand how broader changes in the metabolic capacity of these soil organisms has been altered by anthropogenic $\mathrm{N}$ deposition, and furthermore, whether this response could foster greater soil C storage in our long-term field experiment.

A diverse assemblage of saprotrophic bacteria and fungi secrete extracellular enzymes that mediate the decay of cellulose, hemicellulose, lignin, and chitin, processes that largely control the cycling of C in terrestrial ecosystems (Osono, 2007; Voríšková et al., 2014). Understanding the molecular mechanisms by which anthropogenic $\mathrm{N}$ deposition modify the microbial metabolism of plant and fungal detritus is central to our ability to anticipate the storage and cycling of $\mathrm{C}$ in terrestrial ecosystems. For example, litter decay is largely mediated by lignocellulolytic enzymes of fungal origin and can result in complete metabolism to $\mathrm{CO}_{2}$ (Kirk and Farrell, 1987; D'souza et al., 1999; Polaina and Maccabe, 2007). Some bacteria also can participate in lignocellulose decay, which results in the production of soluble polyphenols $(\sim 60 \%$ of products) with minimal amounts of $\mathrm{CO}_{2}(<4 \%$; Godden et al., 1992; Ahmad et al., 2010; Bugg et al., 2011). Thus, how the composition and function of saprotrophic bacteria and fungi responds to anthropogenic $\mathrm{N}$ deposition has implications for the cycling and storage of $\mathrm{C}$ in the future. Shotgun metagenomics (i.e., the direct sequencing of environmental DNA) can be used to elucidate the genetic potential of complex microbial communities and provides the opportunity to simultaneously explore the taxonomic membership and functional capacity of the community (Fierer et al., 2012; Sharpton, 2014). This technology can provide insight into microbially mediated biogeochemical cycles, but it has rarely been applied to replicated experimental studies of soil microbial communities (Prosser, 2010; Knight et al., 2012; Myrold et al., 2014). Moreover, metagenomic studies in soil have mainly focused on bacteria, although recent improvements to genomic databases have allowed for metagenomic insights into the fungal community as well (Cline and Zak, 2015; Hesse et al., 2015).

Here, we employed shotgun metagenomics and extracellular enzyme assays in a well-replicated, long-term field experiment to decipher whether nearly two decades of experimental $\mathrm{N}$ deposition has altered the metabolic capacity of the soil bacterial and fungal community to metabolize plant and fungal detritus. It is plausible that chronic $\mathrm{N}$ deposition can modify the metabolic capacity of the microbial community that mediates decay, which may elicit a functional response consistent with our biogeochemical observations (Zak et al., 2008; Eisenlord et al., 2013). We used ribosomal and functional gene databases (i.e., RDP and Subsystems, respectively in MGRAST) to gain insight into whether experimental $\mathrm{N}$ deposition altered the taxonomic composition, as well as the metabolic capacity of the soil microbial community. Sequence homology with manually curated gene databases was also employed to explore the genetic capacity of both bacteria and fungi to metabolize lignocellulose (Cline and Zak, 2015). Using these approaches, we obtained insight to the taxonomic composition and metabolic capacity of saprotrophic bacteria and fungi in response to anthropogenic $\mathrm{N}$ deposition in a long-term field study.

\section{MATERIALS AND METHODS}

\section{Site Description and Sample Collection}

We investigated the influence of experimental $\mathrm{N}$ deposition on the functional capacity of the forest floor microbial community in four northern hardwood forest stands in Lower and Upper Michigan, USA (Table 1; Figure S1). The stands span the northsouth geographic range of the northern hardwood forests in the Great Lakes region (Braun, 1950) and lie along a climatic and atmospheric $\mathrm{N}$ deposition gradient. All sites are dominated by sugar maple (Acer saccharum Marsh.) and are otherwise floristically and edaphically similar. The thin Oi horizon is mainly comprised of sugar maple leaf litter and the Oe/Oa horizon is interpenetrated by a dense mat of fine roots $(\sim 0.5 \mathrm{~mm}$ dia.); the Oe/Oa material was used in this study and it is where decay has been reduced. Soils are sandy (85-90\%), well-drained, isotic, frigid Typic Haplorthods of the Kalkaska series. Six plots $(30 \times 30 \mathrm{~m})$ were established at each stand in 1994; three receive ambient $\mathrm{N}$ deposition and three receive experimental $\mathrm{N}$ deposition. Experimental $\mathrm{N}$ deposition consists of $\mathrm{NaNO}_{3}$ pellets broadcast over the forest floor in six equal applications during the growing season (30 $\mathrm{kg} \mathrm{N} \mathrm{ha}^{-1}$ year $\left.^{-1}\right)$; in our study sites, $\mathrm{NO}_{3}^{-}-\mathrm{N}$ comprises $\sim 60 \%$ of atmospheric $\mathrm{N}$ deposition (Zak et al., 2008; Barnard et al., 2013).

Forest floor sampling occurred in late May to early June 2013. Samples from all four sites were taken during a phenologically similar period, a time at which ample moisture supports high rates of microbial activity. Within each $30 \times 30-\mathrm{m}$ plot, 10 random $0.1 \times 0.1-\mathrm{m}$ forest floor samples (Oa/Oe horizons) were collected after removing the Oi horizon. All samples were composited within each plot and hand homogenized in the field. A portion of the homogenized sample was immediately frozen in liquid $\mathrm{N}_{2}$ for nucleic acid extraction; the remainder was kept on ice for enzyme analyses. Samples were transported to the University of Michigan, where they were stored at -4 or $-80^{\circ} \mathrm{C}$ for enzyme analysis and nucleic acid extraction, respectively. 
TABLE 1 | Site, climatic, overstory, and ambient nitrogen deposition rates of four study sites receiving experimental $\mathrm{N}$ additions.

\begin{tabular}{|c|c|c|c|c|}
\hline Characteristic & Site A & Site B & Site C & Site D \\
\hline \multicolumn{5}{|l|}{ LOCATION } \\
\hline Latitude (N) & $46^{\circ} 52^{\prime \prime}$ & $45^{\circ} 33^{\prime \prime}$ & $44^{\circ} 23^{\prime \prime}$ & $43^{\circ} 40^{\prime \prime}$ \\
\hline Longitude $(\mathrm{W})$ & $88^{\circ} 53^{\prime \prime}$ & $84^{\circ} 52^{\prime \prime}$ & $85^{\circ} 50^{\prime \prime}$ & $86^{\circ} 9^{\prime \prime}$ \\
\hline \multicolumn{5}{|l|}{ CLIMATE } \\
\hline Mean annual temperature $\left({ }^{\circ} \mathrm{C}\right)$ & 4.8 & 6.1 & 6.5 & 7.7 \\
\hline Mean annual precipitation (cm) & 91.9 & 93.3 & 92.8 & 86.6 \\
\hline $\begin{array}{l}\text { Ambient N Deposition (Kg N } \\
\text { ha }^{-1} \text { year }^{-1} \text { ) }\end{array}$ & 5.9 & 6.1 & 7.4 & 7.4 \\
\hline \multicolumn{5}{|l|}{ VEGETATION } \\
\hline Overstory biomass (Mg ha $\left.{ }^{-1}\right)$ & 261 & 261 & 274 & 234 \\
\hline $\begin{array}{l}\text { Acer saccharum biomass (Mg } \\
\mathrm{ha}^{-1} \text { ) }\end{array}$ & 237 & 224 & 216 & 201 \\
\hline \multicolumn{5}{|l|}{ ENVIRONMENT } \\
\hline \multicolumn{5}{|l|}{ Leaf Litter (Oe/Oa horizons) } \\
\hline Litter C:N & 63.7 & 57.1 & 52.9 & 43.4 \\
\hline Litter mass (g) & 412 & 396 & 591 & 550 \\
\hline \multicolumn{5}{|l|}{ Soil $(0-10 \mathrm{~cm})$} \\
\hline Sand (\%) & 85 & 89 & 89 & 87 \\
\hline $\mathrm{pH}\left(1: 1 \mathrm{soil} / \mathrm{H}_{2} \mathrm{O}\right)$ & 4.8 & 5.0 & 4.5 & 4.7 \\
\hline Base saturation, \% & 71 & 96 & 73 & 80 \\
\hline
\end{tabular}

Data represent site, climatic, overstory, and ambient nitrogen deposition rates of four study sites receiving experimental $N$ additions. Reprinted by Permission, ASA, CSSA, SSSA.

\section{Enzyme Analysis}

We measured the potential activity of extracellular enzymes that catalyze the metabolism of two common plant litter compounds, cellulose (cellobiohydrolase; EC 3.2.1.91), and lignin (peroxidase, EC 1.11.1.7; phenol oxidase, EC 1.10.3.2). We also assayed $\beta-1,4-$ $\mathrm{N}$-acetylglucosaminidase (NAGase; EC 3.1.6.1), which catalyzes the metabolism of chitin, a component of fungal cell walls. Enzyme assays were initiated $72 \mathrm{~h}$ after field sampling and were performed according to Saiya-Cork et al. (2002). Briefly, a fluorometric assay was used to determine cellobiohydrolase and NAGase activity, in which methylumbelliferone-linked cellobioside or $\mathrm{N}$-acetylglucosamine was used as the respective substrates. Peroxidase and phenol oxidase activity was measured using a colorimetric assay with L-dihydroxyphenylalanine (LDOPA) as the substrate with the addition of hydrogen peroxide for the peroxidase assay. All enzyme assays were performed in 96-well plates on a Synergy HT microplate reader (Gen5, version 2.00.18, BioTek, Winooski, VT, USA). Enzyme activity potential was defined as units, wherein 1 unit $=1 \mu \mathrm{mol} \mathrm{h}^{-1}$ of the oxidized reaction product relative to the dry weight of forest floor. The effects of location, experimental $\mathrm{N}$ deposition, and their combined interaction on enzyme activity potential was determined by analysis of variance (ANOVA); means were compared with a protected Fisher's LSD in the R environment using the stats package (Version 3.01; R Code Team, 2013).

\section{DNA Extraction and Metagenome Generation}

Genomic DNA was extracted from $0.60 \mathrm{~g}$ (total fresh weight; six replicate extractions) of homogenized forest floor samples using a PowerLyzer PowerSoil DNA isolation kit with a PowerLyzer 24 homogenizer (MoBio Laboratories, Carlsbad, CA). To increase the quality and yield of nucleic acids, we modified the manufacturer's protocol by the initial addition of $250 \mu \mathrm{L}$ phenol:chloroform:isoamyl alcohol (25:24:1; $\mathrm{pH} 6.7)$, bead beating at $4000 \mathrm{rpm}$ for $45 \mathrm{~s}$, centrifugation at $4^{\circ} \mathrm{C}$; and overnight ethanol precipitation at $-20^{\circ} \mathrm{C}$. Extracted DNA was purified using a PowerClean DNA Cleanup kit (MoBio). Purified DNA quality was determined using an ND8000 Nanodrop (Thermo Scientific, Waltham, MA, USA) and quantified by Quant-iT PicoGreen (Invitrogen, Carlsbad, CA, USA) on a Synergy HT fluorometer.

Purified environmental DNA was submitted for shotgun sequencing at the University of Michigan DNA sequencing core. Samples were barcoded by plot $(n=24)$ and pooled in equimolar concentrations on six lanes of an Illumina Hiseq 2500 (Illumina, San Diego, CA, USA), with 150 base single-end reads. Illumina reads containing adapter sequences were removed using Cutadapt version 1.7.1 (Martin, 2011). All metagenome sequence data have been deposited and are publically available in MGRAST (Meyer et al., 2008) under accession numbers 4614815.34614838.3.

\section{Taxonomic Identification}

Taxonomic information was assessed from the shotgun metagenomes using the "best-hit classification" function within MG-RAST against the RDP database (Cole et al., 2014). Hits were taxonomically assigned using a maximum $e$-value of 1 $\times 10^{-5}$, minimum percent identity of $80 \%$, and a minimum alignment length of $50 \mathrm{bp}$.

\section{Functional Gene Identification}

To determine the impact of experimental $\mathrm{N}$ deposition on the metabolic potential of the forest floor microbial community, we considered the forest floor metagenomes as (i) functional pathways using a Subsystems-based approach in MG-RAST (Overbeek et al., 2014), (ii) bacterial lignocelluloytic gene composition using the SEED database, and (iii) fungal lignocelluloytic gene composition using BLASTN (Altschul et al., 1990) queries against manually-curated databases (Table S1; Cline and Zak, 2015). In this way, we obtained complimentary assessments of the lignocellulolytic capacity to determine how the forest floor microbial community may be affected by experimental $\mathrm{N}$ deposition. For Subsystems functional pathway analysis, metagenome hits were annotated using a maximum $e$-value of $1 \times 10^{-5}$, a minimum percent identity of $60 \%$, and a minimum alignment length cutoff of 25 amino acids. All metagenomes were first considered at broad classifications (i.e., Subsystem level one) to determine what functional categories may be affected by experimental $\mathrm{N}$ deposition. We further examined the level-one classifications "Carbohydrates," "Metabolism of Aromatic Compounds," and "Respiration" at a more resolved level (i.e., Subsystem level three) to gain further insight into a possible microbial mechanism reducing decay in our experiment. Throughout this manuscript, Subsystem level one categories will be termed "classifications" and Subsystem level 3 categories will be termed "pathways." Gene assignments 
were standardized to the number of sequences with predicted functions (sensu; Fierer et al., 2012).

To determine the effect of experimental $\mathrm{N}$ deposition on specific functional genes mediating the decay of plant and fungal detritus, databases were constructed to determine the relative abundance of genes encoding enzymes mediating their metabolism. Metagenome sequences were assigned to 25 genes in 6 substrate categories (Table S1) using the SEED model within MG-RAST (Meyer et al., 2008). Due to the dominance of bacterial sequences in the MG-RAST databases, fungal metabolic potential was analyzed following the creation of 12 gene databases in 5 substrate categories, created collectively from the Carbohydrate Active Enzyme database (CAZy), Peroxibase, the Functional Gene Repository, and NCBI reference sequences (Fawal et al., 2013; Fish et al., 2013; Lombard et al., 2014; Tatusova et al., 2015). By doing so, the taxonomic assignment of DNA sequences enabled the creation of fungal gene databases separate and distinct from bacteria (sensu; Cline and Zak, 2015). Functional gene sequences were accessed from each database on January 13-15, 2015 and are available for download on GitHub (https://github.com/zacf/UM-gradient-metagenome-databases).

Sequences from shotgun metagenomes were assigned to functional genes by substrate category, including genes associated with the decay of cellulose, chitin, galactosecontaining oligosaccharides, lignin, pectin, starch, and xylan (Table S1). For each metagenome, the abundance of genes involved in the decay of each substrate category (e.g., cellulose, lignin, xylan) was calculated following the assignment of metagenome sequences to functional gene databases using BLASTN. Bacterial and fungal genes were assigned using $60 \%$ minimum sequence homology, $e$-value cut-off of $1 \times 10^{-5}$, minimum alignment $30 \mathrm{bp}$. Gene assignments were standardized to the number of sequences with predicted functions for each metagenome $(n=24)$.

\section{Statistical Analyses of Metagenomic Data}

Prior to statistical analysis, only those gene families that occurred in each of the 4 forest stands exposed to either ambient or experimental $\mathrm{N}$ deposition were chosen for further analysis to reduce the inclusion of erroneously annotated reads. For sequences where multiple Subsystem or gene categories were assigned, all categories were counted as additional hits (sensu; Žifcáková et al., 2016). All univariate analyses were performed in the R environment (Version 3.01; R Code Team, 2013). Functional and taxonomic metagenome abundance tables were normalized using the "normalize" function in matR prior to statistical analysis (Version 1.0.0; Braithwaite and Keegan, 2013). The change in relative abundance of hits attributed to functional genes and pathways were assessed by two-way ANOVA with site, treatment, and their interaction as factors. When applicable, $P$-values were corrected for multiple comparisons using the Benjamini and Hochberg False Discovery Rate correction (Benjamini and Hochberg, 1995). In this circumstance, an "adjusted P" value is presented.

Calculation of beta-diversity indices and associated statistics were executed in Primer (version 6, Primer-E Ltd., Plymouth, UK). A Euclidian distance matrix based on
matR normalized metagenome abundance was generated, from which the significance of compositional differences between microbial functional assemblages exposed to ambient and experimental $\mathrm{N}$ deposition were determined by permutational multivariate analysis of variance (PerMANOVA; Anderson, 2001). Contributions of each functional pathway to the multivariate dissimilarity between metagenomes under ambient and experimental $\mathrm{N}$ deposition were determined using Similarity Percentage analysis (SIMPER; Clarke, 1993).

\section{RESULTS AND DISCUSSION}

\section{A Sustained Decline in Lignolytic Potential under Experimental N Deposition}

Experimental $\mathrm{N}$ deposition reduced lignocellulolytic enzyme activity and changed the metagenomic composition of the microbial community inhabiting decaying forest floor, providing indirect evidence that compositional shifts elicited a functional response in our long-term field experiment. The activity of two extracellular enzymes mediating plant litter and humus decay, cellobiohydrolase ( $-52 \%$ change from ambient; $P=0.02$; Figure 1) and peroxidase $(-50 \% ; P=0.01)$, were significantly lower under experimental $\mathrm{N}$ deposition. Although phenol oxidase exhibited the same response, the reduction of its activity under experimental $\mathrm{N}$ deposition was not statistically significant $(-21 \% ; P=0.10)$. N-acetyl-glucosaminidase (NAGase) activity, which catalyzes the metabolism of chitin, trended higher under experimental $\mathrm{N}$ deposition, but this increase also was not significant $(+61 \% ; P=0.37)$. Although, mean enzyme activities varied across the four sites $(P<0.05)$, experimental $\mathrm{N}$ deposition negatively affected cellobiohydrolase, peroxidase, and phenol oxidase activity similarly, as we observed no significant site by treatment interaction.

The results we present here are consistent with previous observations that experimental $\mathrm{N}$ deposition has reduced the

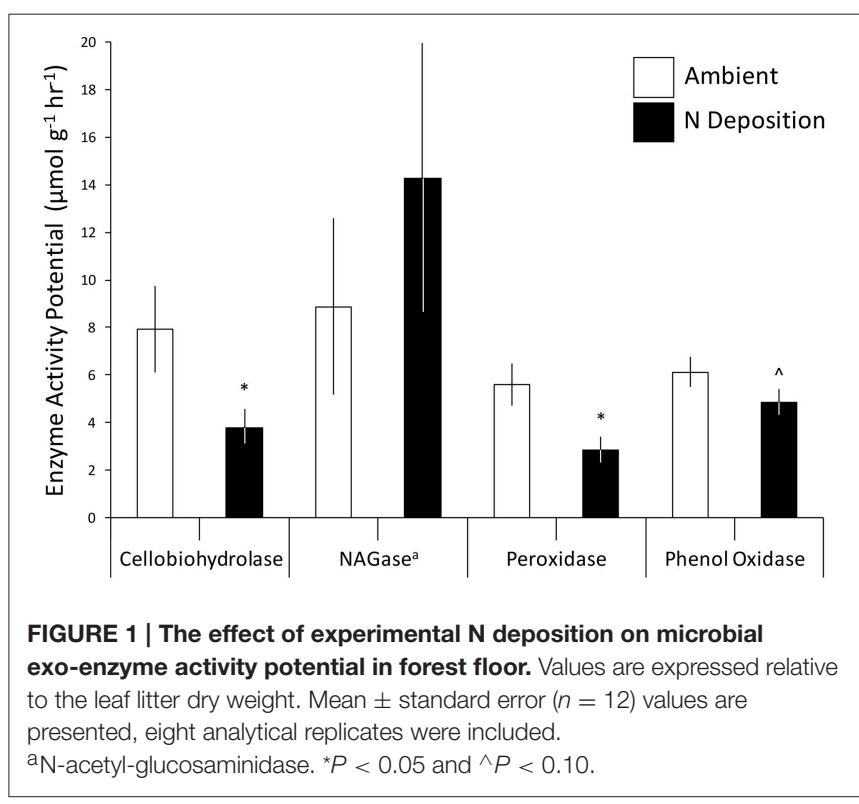


activities of extracellular enzymes mediating plant litter and humus decay (Deforest et al., 2004, 2005; Waldrop et al., 2004; Edwards et al., 2011). In this study, cellobiohydrolase activity was lower under experimental $\mathrm{N}$ deposition as compared to the ambient treatment (Figure 1); whereas, it was previously determined that experimental $\mathrm{N}$ deposition leads to lower cellobiohydrolase activity, though non-significantly (Edwards et al., 2011). It is plausible that this sustained decline in enzymatic activity has decreased microbial metabolism of plant litter and humus, resulting in soil organic matter (SOM) accumulation and dissolved organic carbon (DOC) leaching previously documented in our long-term field experiment.

\section{Taxonomic Assessment of the Soil Microbiome}

We analyzed high-quality short reads to evaluate whether experimental $\mathrm{N}$ deposition has affected the taxonomic composition and functional capacity of the microbial communities inhabiting decaying forest floor. Sequencing and quality control produced 717,933,077 high-quality reads totaling 108.4 Gbases. Across the 24 metagenomes (e.g., 12 plots receiving ambient $\mathrm{N}$ deposition and 12 plots receiving experimental $\mathrm{N}$ deposition), $26-33 \%$ could be assigned to functional categories, percentages that are similar to other metagenomic surveys of soil samples (Fierer et al., 2012; Uroz et al., 2013).

We assessed the taxonomic classification of metagenomic hits using the RDP database within MG-RAST, and as expected, the metagenomes were dominated by Bacteria ( $\sim 98 \%$ of annotated reads). Fungi represented $1.0 \pm 0.6 \%$ of annotated reads, whereas Archaea represented $0.03 \pm 0.007 \%$ of reads. The metagenomes were dominated by the bacterial phyla Actinobacteria (Figure S2; $\sim 46 \%)$, Proteobacteria $(\sim 26 \%)$, and Bacteroidetes $(\sim 11 \%)$. However, the taxonomic composition of the soil microbial community was not significantly affected by experimental $\mathrm{N}$ deposition at the phylum (PerMANOVA; $\mathrm{P}=0.27$ ), class $(\mathrm{P}=$ $0.30)$, or species $(P=0.21)$ level. These observations provide evidence that the biogeochemical responses we have documented arise from a reduction in functional capacity of the extant community under experimental $\mathrm{N}$ deposition, rather than a shift in taxonomic composition that elicited a concomitant reduction in function. It also is consistent with a recently completed study demonstrating the experimental $\mathrm{N}$ deposition did not alter the total community of soil bacteria or fungi, but did modify the community of organisms who were active under experimental $\mathrm{N}$ deposition (Freedman et al., 2015).

The dominance of Bacteria in annotated reads from soil metagenomes is common ( $\sim 83-98 \%$; Fierer et al., 2012; Uroz et al., 2013; Navarrete et al., 2015), because annotation databases are biased toward culturable bacteria. Moreover, it is plausible that the underrepresentation of fungal genes in annotation databases leads to low coverage of fungi in soil metagenomic analyses (Wooley et al., 2010; Myrold et al., 2014). In addition to annotation biases, many fungal genes contain intronic sequences, which require long reads for accurate annotation. For this reason, the fungal contribution to soil metabolic function may be further resolved using a transcriptomic approach, as evidenced by a higher proportion of fungal transcripts in recent soil metatranscriptomes ( 73\%; Hesse et al., 2015; Žifcáková et al., 2016) as compared to the proportion of fungal genes in soil metagenomes (2-17\%).

\section{Effects of N Deposition on Functional Pathways of the Soil Microbiome}

All metagenomes were initially assessed from a broad to fine level of functional resolution using Subsystems classifications within MG-RAST. At the broadest category (i.e., level 1), there was no difference in the relative abundance (Adjusted $\mathrm{P}>$ 0.10 ) or composition (Figure S3; PerMANOVA; P $=0.60$ ) of hits assigned to each Subsystem $(n=28$ Subsystem level 1 classifications). To further understand the impact of chronic $\mathrm{N}$ deposition on the genes mediating organic matter decay, we chose to focus our analysis on metagenomic hits assigned to the following Subsystem level one classifications: Carbohydrates, Metabolism of Aromatic Compounds, and Respiration. Within these Subsystem-level-one classifications, we analyzed the change in relative abundance of genes associated with each level-three pathway.

Experimental $\mathrm{N}$ deposition significantly and differentially affected the relative abundances of genes associated with 32 of 103 total pathways within the Carbohydrate classification (adjusted $\mathrm{P}<0.05$; Figure 2, Table S2). The composition of functional pathways within the Carbohydrates classification was also affected by experimental $\mathrm{N}$ deposition (PerMANOVA; $\mathrm{P}$ $=0.057$; Figure 3A). To determine the relative contribution of gene pathways within the Carbohydrate classification to compositional dissimilarity between ambient and experimental $\mathrm{N}$ deposition assemblages, SIMPER analysis was performed (Table 2). SIMPER determined that pathways mediating unknown carbohydrate utilization $(26.8 \%$ of community dissimilarity), malonate decarboylation (12.6\%), and GlcNAc 2 catabolism (10.1\%) contributed the greatest to dissimilarity in the functional capacity of the microbial community exposed to ambient and experimental $\mathrm{N}$ deposition. All sites were affected by experimental $\mathrm{N}$ deposition in the same fashion, as there were no significant site by treatment interactions.

The forest floor metagenomes indicated that gene pathways mediating bacterial carbohydrate metabolism were favored under experimental $\mathrm{N}$ deposition. For example, of the significant Subsystem level 3 pathways, 27 of 32 increased in abundance in the experimental $\mathrm{N}$ deposition treatment. Among the most positively affected by experimental $\mathrm{N}$ deposition were genes mediating chitin utilization ( $\sim 5 \%$ change from ambient; adjusted $\mathrm{P}=0.05)$; this change occurred concomitantly with a nonsignificant increase in NAGase activity $(+61 \% ; \mathrm{P}=0.37$; Figure 1). Chitin is a primary component of fungal cell wall; thus, an increase in genes meditating its metabolism may suggest greater fungal necromass under future rates of $\mathrm{N}$ deposition. Understanding how $\mathrm{N}$ deposition affects the decay of microbial necromass can help predict how this important, although poorly understood, C pool in soil may be altered by climate change (Clemmensen et al., 2013; Crowther et al., 2015). Genes 


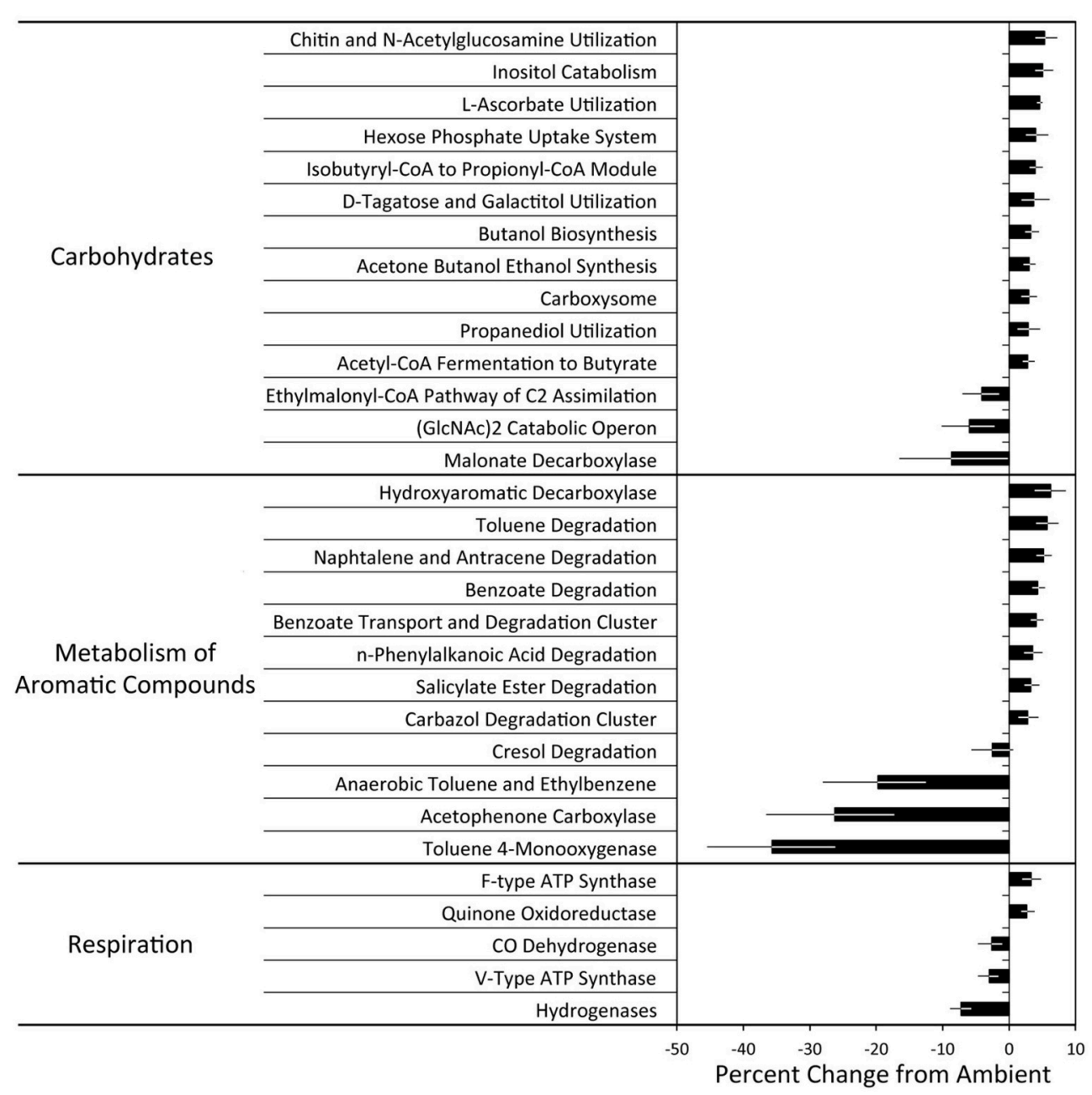

FIGURE 2 | The effect of experimental $\mathbf{N}$ deposition on the relative abundance of SEED subsystem level 3 functional pathways. All pathways presented were significantly different in abundance and exhibited a greater than $\pm 2.5 \%$ change between the ambient and experimental $\mathrm{N}$ deposition treatment (adjusted $P<$ 0.05). Results of all significant pathways can be found in Tables S2, S3, and S4.

mediating L-ascorbate utilization also increased in abundance under $\mathrm{N}$ deposition $(\sim 5 \%$; adjusted $\mathrm{P}=0.01)$ and accounted for $\sim 8 \%$ of the functional dissimilarity between the microbial communities exposed to ambient and experimental $\mathrm{N}$ deposition. L-ascorbate (i.e., vitamin C) is an important metabolite for most living organisms. Thus, given the dominance of bacterial reads in the MG-RAST annotated metagenomes (i.e., 98\%), increased utilization of $\mathrm{L}$-ascorbate under $\mathrm{N}$ deposition supports the hypothesis that bacterial metabolism could be favored under future rates of $\mathrm{N}$ deposition, and may mediate increased $\mathrm{C}$ storage in our long-term field experiment.

While many of the significantly affected gene pathways mediating carbohydrate metabolism increased in abundance in response to experimental $\mathrm{N}$ deposition, some responded negatively. For example, experimental $\mathrm{N}$ deposition reduced the abundance of genes mediating malonate decarboxylation ( $-9 \%$; adjusted $\mathrm{P}=0.04$ ), which also accounted for $\sim 13 \%$ of the functional dissimilarity between the microbial communities exposed to ambient and experimental $\mathrm{N}$ deposition. Malonate is a common organic acid in soil; it is a TCA cycle intermediate and also is involved in soil carbon dynamics and nutrient solubilization (Oburger et al., 2011). We also observed a $6 \%$ decrease in the catabolic operon of the chitin disaccharide, N,N-diacetylchitobiose ( $\mathrm{GlcNAc}_{2}$; adjusted $P=0.01$ ), which accounted for $\sim 10 \%$ of the dissimilarity between the functional capacity of the microbial communities exposed to ambient and experimental $\mathrm{N}$ deposition. Bacterial chitin degradation pathways are diverse and phylogenetically widespread (Beier and Bertilsson, 2013; Zimmerman et al., 2013). While genes encoding chitinases are well-represented in functional gene databases, much of what is known of gene-operons conferring $\mathrm{GlcNAc}_{2}$ degradation capability (e.g., regulators and transporters) is from organisms inhabiting the marine environment (e.g., Vibrio sp.; Meibom et al., 2004). Thus, this result is likely indicative of an ecologically irrelevant subset of operonic genes and not of the entire community. 
A

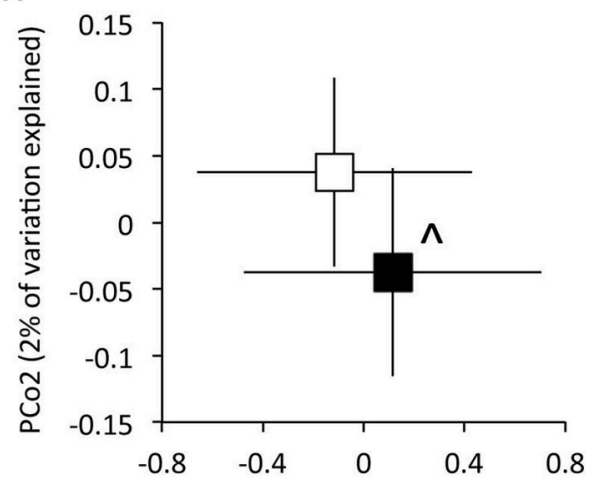

B $\quad$ PCo1 (97\% of variation explained)
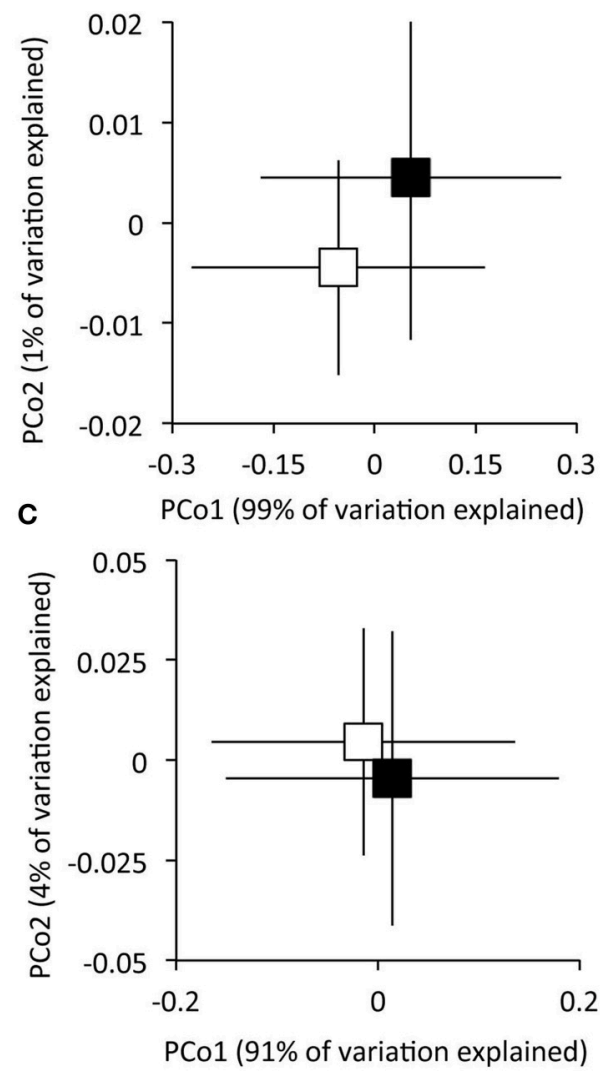

FIGURE 3 | The effect of experimental $\mathbf{N}$ deposition on the composition of functional gene pathways within the Carbohydrates (A), Metabolism of Aromatic Compounds (B), and Respiration (C) SEED subsystem classifications. Ordinations were obtained from Principle Coordinates Analysis on based Euclidian distances of matR normalized data. Open and closed boxes indicate the composition of functional gene pathways in the ambient and experimental $\mathrm{N}$ deposition treatment, respectively. ${ }^{\wedge} P=0.057$ by PerMANOVA.

Within the Metabolism of Aromatic Compounds (MAC) Subsystem level one classification, experimental $\mathrm{N}$ deposition significantly affected genes associated with 21 of 32 level three functional pathways (Figure 2, Table S3). All sites were affected by experimental $\mathrm{N}$ deposition in the same fashion, as there were no significant site by treatment interactions. The
TABLE 2 | Contribution of gene pathways to compositional dissimilarity of the Carbohydrates classification as indicated by SIMPER analysis.

\begin{tabular}{lcc}
\hline Variable & Contrib\% & Cum.\% \\
\hline Unknown carbohydrate utilization $^{\mathrm{a}}$ & 26.8 & 26.8 \\
Malonate decarboxylase & 12.6 & 39.4 \\
GlcNAc 2 Catabolic Operon & 10.1 & 49.5 \\
Ethylmalonyl-CoA pathway of C2 assimilation & 8.3 & 57.7 \\
Hexose Phosphate Uptake System & 8.1 & 65.9 \\
L-ascorbate utilization & 7.6 & 73.5 \\
L-fucose utilization & 5.6 & 79.1 \\
Xyloglucan utilization & 3.9 & 83.0 \\
Alpha-Amylase locus in Streptocococcus & 2.0 & 85.0 \\
Soluble methane monooxygenase (sMMO) & 1.6 & 86.5
\end{tabular}

${ }^{a}$ containing Fructose-bisphosphate aldolase.

composition of functional pathways within the Metabolism of Aromatic Compounds classification was not affected by experimental $\mathrm{N}$ deposition (Figure 3B; PerMANOVA; $\mathrm{P}=$ 0.26).

Similar to carbohydrate metabolism, particular pathways of bacterial aromatic compound metabolism were favored under future rates of $\mathrm{N}$ deposition. Of the significant level three pathways, 16 of 21 increased in abundance under experimental $\mathrm{N}$ deposition. Among the most positively affected were the hydroxyaromatic decarboxylase and benzoate degradation pathways, which increased in abundance under experimental $\mathrm{N}$ deposition by 6 and $4 \%$ respectively, as compared to the ambient treatment (adjusted $\mathrm{P}<0.05$ ). This suggests an increased importance of bacterial decarboxylation of hydroaromatic compounds (e.g., benzoate) under future rates of $\mathrm{N}$ deposition. Genes mediating anaerobic toleuene degradation and toluene-4monooxygenase were most negatively affected by experimental $\mathrm{N}$ deposition ( -20 and $-36 \%$ change from ambient, respectively; adjusted $\mathrm{P}<0.05$ ), but likely are ecologically irrelevant differences in the microbial functional capacity due to the well-drained nature of the sandy soils in our experiment. We did not expect much, if any toluene, to be present in the soils of our study, and the emission of toluene during litter decomposition is negligible (Gray et al., 2010). Given the similarity of many of these compounds with poly-phenolic compounds whose leaching has increased under experimental $\mathrm{N}$ deposition (Pregitzer et al., 2004), the increased metabolism of aromatic compounds will be a favored microbial trait as rates of $\mathrm{N}$ deposition continue to increase in the future (Freedman and Zak, 2014).

The relative abundance of genes associated with 15 of 42 level three pathways within the Respiration classification were significantly affected by experimental $\mathrm{N}$ deposition (Figure 2; Table S4). All sites were affected by experimental $\mathrm{N}$ deposition in the same fashion, as there were no significant site by treatment interactions. The composition of functional pathways within the Respiration classification also was not affected by experimental $\mathrm{N}$ deposition (Figure 3C; PerMANOVA; $\mathrm{P}=0.42$ ).

Analysis of functional pathways within the Respiration classification was mixed, as 7 of 15 significant level three 
pathways increased in abundance in the experimental $\mathrm{N}$ deposition treatment (Figure 2). For example, the abundance of genes encoding bacterial and eukaryotic ATPases, enzymes that dephosphorylate ATP, were differentially affected by experimental $\mathrm{N}$ deposition. Experimental $\mathrm{N}$ deposition led to an increase in the relative abundance of bacterial (F-type; $+3 \%$; adjusted $\mathrm{P}=0.04$ ) and a decrease in eukaryotic ATPases (V-type; $-3 \%$; adjusted $\mathrm{P}=0.01)$. These results support a stimulation of saprotrophic bacterial activity and a suppression of fungi under future rates of $\mathrm{N}$ deposition (Edwards et al., 2011; Freedman and Zak, 2014, 2015b). Genes encoding hydrogenases were most negatively affected $(-7 \%$; adjusted $\mathrm{P}=0.03)$ by the experimental $\mathrm{N}$ deposition treatment. $\mathrm{N}_{2}$-fixing soil microorganisms release substantial amounts of $\mathrm{H}_{2}$ as a byproduct of nitrogenase activity, which is suppressed by $\mathrm{N}$ fertilization. (Dasilva et al., 1993; Freedman et al., 2013; Berthrong et al., 2014). It is possible that a suppression of microbial $\mathrm{N}_{2}$ fixation is occurring with experimental $\mathrm{N}$ deposition, leading to less $\mathrm{H}_{2}$ emission in soils and lower hydrogenase activity. While soil represents the largest sink of atmospheric $\mathrm{H}_{2}$, contributing about $75 \%$ to the total budget (Prather, 2003), we do not expect the biochemical pathway to have any effect on soil C storage in our long-term field experiment.

\section{Effect of Simulated N Deposition on the Abundance of Functional Genes Mediating SOM Decay}

We estimated the relative abundance of individual bacterial and fungal lignocellulolytic genes mediating litter decay using a curated database of genes (Table S1). This enabled us to assess how experimental $\mathrm{N}$ deposition affects specific genes encoding enzymes mediating lignocellulose decay. Experimental $\mathrm{N}$ deposition significantly reduced the relative abundance of bacterial genes mediating the decay of chitin (Figure S4; $-8.5 \%$; adjusted $\mathrm{P}=0.03$ ), and this effect was consistent across sites ( site $\times$ treatment; adjusted $\mathrm{P}=0.11$ ). The relative abundance of bacterial genes mediating the decay of other substrates (i.e., cellulose, hemicellulose, lignin, pectin, and starch) was not affected by experimental $\mathrm{N}$ deposition. When considered together, the composition of bacterial lignocellulolytic functional genes was affected in a site-specific manner, as indicated by a significant site by treatment interaction (Figure S5; PerMANOVA; $\mathrm{P}=0.03$ ). Pairwise tests indicate that experimental $\mathrm{N}$ deposition altered the composition of bacterial lignocellulolytic genes in Sites $\mathrm{B}$ (Pairwise $\mathrm{P}=0.01$ ) and $\mathrm{D}$ (Pairwise $\mathrm{P}=0.01$ ), but not in Sites $\mathrm{A}$ and $\mathrm{C}$ (Pairwise $\mathrm{P}>$ 0.20 ). This contrasts with previous work in which we observed and increased relative abundance of bacterial LMCO genes under experimental $\mathrm{N}$ deposition (Freedman and Zak, 2014). Bacterial communities exhibit seasonal community dynamics, as well as successional changes during leaf decay (Lipson and Schmidt, 2004; Torres et al., 2005; Chapman et al., 2013; Freedman and Zak, 2015a). It is plausible that saprotrophic bacteria respond to experimental $\mathrm{N}$ deposition, as well as other agents of environmental change, in a seasonally or temporally dependent manner. To more definitively understand the bacterial response to future rates of $\mathrm{N}$ deposition, we must gain a greater understanding of the temporal robustness of their response.

The relative abundance of fungal genes mediating cellulose, hemicellulose, lignin, pectin, and xylan decay also were not affected by experimental $\mathrm{N}$ deposition (adjusted $\mathrm{P}>0.05$ ). When considered together, the composition of fungal functional genes was not affected by experimental $\mathrm{N}$ deposition (PerMANOVA; $\mathrm{P}=0.42$ ); however, the composition of fungal lignocellulolytic genes did differ between sites $(\mathrm{P}=0.02)$.

Experimental $\mathrm{N}$ deposition has altered the bacterial lignocellulolytic potential in a site-dependent manner; whereas, the functional potential of the saprophytic fungal community is unaffected by chronic $\mathrm{N}$ deposition. However, previous observations indicate that soil fungi down-regulate the expression of gene with lignolytic function under experimental $\mathrm{N}$ deposition (Edwards et al., 2011; Hesse et al., 2015). Results presented here supports the hypothesis that the lignocellulolytic potential of the fungal community was not affected by future rates of $\mathrm{N}$ deposition; however, the expression of these fungal genes (i.e., the active community) was negatively effected by this agent of environmental change (Edwards et al., 2011; Freedman et al., 2015).

\section{Toward a Microbial Mechanism Mediating Increased C Storage under Future Rates of N Deposition}

Results presented here indicate that future rates of $\mathrm{N}$ deposition alter the functional capability of the soil microbial community inhabiting decaying leaf litter, namely, the suppression of the lignocellulolytic enzymatic capacity of the soil microbial community, and the increased prevalence of bacterial gene pathways implicated in litter decay. These enzymatic and metagenomic changes underlie a biogeochemical response, as nearly 20 years of experimental $\mathrm{N}$ deposition has reduced litter decay in our long-term experiment (Zak et al., 2008), indicative of a phenomenon commonly observed among terrestrial ecosystems exposed to simulated N deposition (Frey et al., 2004; Liu and Greaver, 2010; Maaroufi et al., 2015). The decreased enzyme activities we observed are consistent with the suppression of fungal laccase expression in our experiment $(-80 \%$; Edwards et al., 2011). Lignocellulolytic enzymes of fungal origin have a higher redox potential than their bacterial counterparts (Kirk and Farrell, 1987; D'souza et al., 1999; Polaina and Maccabe, 2007); thus, an increase in bacterial gene pathways mediating aromatic compound and carbohydrate metabolism may not be sufficient to offset the oxidative potential lost by a reduction in fungal lignocelluloytic gene expression. Further, future rates of $\mathrm{N}$ deposition favor gene pathways associated with saprotrophic bacteria, whose litter decay capacity is characterized by the production of soluble polyphenols with minimal $\mathrm{CO}_{2}$ production (Ahmad et al., 2010; Bugg et al., 2011). Data presented here together with previous work supports the hypothesis that the ascendance of saptrotrophic bacteria and the suppression of saprotrophic fungi may mediate increased C storage in our longterm field experiment (Edwards et al., 2011; Freedman and Zak, 2014). 


\section{CONCLUSIONS}

In this study, we present evidence that nearly 20 years of experimental $\mathrm{N}$ deposition has resulted in a sustained decline in the decay capability of the forest floor microbial community, which occurred concomitantly with changes in the relative abundance of functional pathways mediating the metabolism of carbohydrates and aromatic compounds, as well as respiration. Furthermore, bacterial gene pathways mediating the metabolism of carbohydrates and aromatic compounds were favored by experimental $\mathrm{N}$ deposition; whereas, the abundance and composition of fungal lignocellulolytic genes were unchanged by this agent of environmental change. Results presented here provide evidence that changes in the functional capacity of saprotrophic soil microorganisms mediate how anthropogenic $\mathrm{N}$ deposition slows the cycling and increases the storage of $\mathrm{C}$ in soil.

\section{AUTHOR CONTRIBUTIONS}

DZ conceived the study. All authors carried out the research. ZF analyzed the data and prepared the first draft of the manuscript.

\section{REFERENCES}

Ahmad, M., Taylor, C. R., Pink, D., Burton, K., Eastwood, D., Bending, G. D., et al. (2010). Development of novel assays for lignin degradation: comparative analysis of bacterial and fungal lignin degraders. Mol. Biosyst. 6, 815-821. doi: 10.1039/b908966g

Altschul, S. F., Gish, W., Miller, W., Myers, E. W., and Lipman, D. J. (1990). Basic local alignment search tool. J. Mol. Biol. 215, 403-410. doi: 10.1016/S00222836(05)80360-2

Anderson, M. J. (2001). A new method for non-parametric multivariate analysis of variance. Austral Ecol. 26, 32-46. doi: 10.1111/j.1442-9993.2001.01070.pp.x

Barnard, R. L., Osborne, C. A., and Firestone, M. K. (2013). Responses of soil bacterial and fungal communities to extreme desiccation and rewetting. ISME J. 7, 2229-2241. doi: 10.1038/ismej.2013.104

Beier, S., and Bertilsson, S. (2013). Bacterial chitin degradationmechanisms and ecophysiological strategies. Front. Microbiol. 4:149. doi: 10.3389/fmicb.2013.00149

Benjamini, Y., and Hochberg, Y. (1995). Controlling the false discovery rate - a practical and powerful approach to multiple testing. J. R. Stat. Soc. B Methodol. 57, 289-300.

Berthrong, S. T., Yeager, C. M., Gallegos-Graves, L., Steven, B., Eichorst, S. A., Jackson, R. B., et al. (2014). Nitrogen fertilization has a stronger effect on soil nitrogen-fixing bacterial communities than elevated atmospheric CO2. Appl. Environ. Microbiol. 80, 3103-3112. doi: 10.1128/AEM.0 4034-13

Braithwaite, D. T., and Keegan, K. P. (2013). matR: Metagenomics Analysis Tools for $R$. R package version 1.0.

Braun, E. L. (1950). Deciduous Forests of Eastern North America. New York, NY: Macmillan Publishing Co, Inc.

Bugg, T. D. H., Ahmad, M., Hardiman, E. M., and Rahmanpour, R. (2011). Pathways for degradation of lignin in bacteria and fungi. Nat. Prod. Rep. 28, 1883-1896. doi: 10.1039/clnp00042j

Chapman, S. K., Newman, G. S., Hart, S. C., Schweitzer, J. A., and Koch, G. W. (2013). Leaf litter mixtures alter microbial community development: mechanisms for non-additive effects in litter decomposition. PLoS ONE 8:62671. doi: 10.1371/journal.pone.0062671

Clarke, K. R. (1993). Non-parametric multivariate analyses of changes in community structure. Aust. J. Ecol. 18, 117-143. doi: 10.1111/j.14429993.1993.tb00438.x
All authors were involved in the revision of the draft manuscript and have agreed to the final content.

\section{FUNDING}

Grants from the U. S. Department of Energy's BER program, the NSF LTREB program, and USDA McIntire-Stennis Program provided support for our work.

\section{ACKNOWLEDGMENTS}

We thank Karl Romanowicz for his work in sample preparation and Will Argiroff for his assistance in shotgun metagenome analyses. We also wish to thank our two anonymous reviewers as well as other members of the Zak lab for their thoughtful feedback on this manuscript.

\section{SUPPLEMENTARY MATERIAL}

The Supplementary Material for this article can be found online at: http://journal.frontiersin.org/article/10.3389/fmicb. 2016.00259

Clemmensen, K. E., Bahr, A., Ovaskainen, O., Dahlberg, A., Ekblad, A., Wallander, H., et al. (2013). Roots and associated Fungi drive longterm carbon sequestration in Boreal Forest. Science 339, 1615-1618. doi: $10.1126 /$ science. 1231923

Cline, L. C., and Zak, D. R. (2015). Soil microbial communities are shaped by plantdriven changes in resource availability during secondary succession. Ecology 96, 3374-3385. doi: 10.1890/15-0184.1

Cole, J. R., Wang, Q., Fish, J. A., Chai, B., Mcgarrell, D. M., Sun, Y., et al. (2014). Ribosomal Database Project: data and tools for high throughput rRNA analysis. Nucleic Acids Res. 42, D633-D642. doi: 10.1093/nar/gkt1244

Crowther, T. W., Sokol, N. W., Oldfield, E. E., Maynard, D. S., Thomas, S. M., and Bradford, M. A. (2015). Environmental stress response limits microbial necromass contributions to soil organic carbon. Soil Biol. Biochem. 85, 153-161. doi: 10.1016/j.soilbio.2015.03.002

Dasilva, P. M., Tsai, S. M., and Bonetti, R. (1993). Response to inoculation and Nfertilization for increased yield and Biological Nitrogen-Fixation of common bean (Phaseolus-Vulgaris L). Plant Soil 152, 123-130. doi: 10.1007/BF00016341

Deforest, J. L., Zak, D. R., Pregitzer, K. S., and Burton, A. J. (2004). Atmospheric nitrate deposition, microbial community composition, and enzyme activity in northern hardwood forests. Soil Sci. Soc. Am. J. 68, 132-138. doi: $10.2136 /$ sssaj2004.1320

Deforest, J. L., Zak, D. R., Pregitzer, K. S., and Burton, A. J. (2005). Atmospheric nitrate deposition and enhanced dissolved organic carbon leaching: test of a potential mechanism. Soil Sci. Soc. Am. J. 69, 1233-1237. doi: $10.2136 /$ sssaj2004.0283

D’souza, T. M., Merritt, C. S., and Reddy, C. A. (1999). Lignin-modifying enzymes of the white rot basidiomycete Ganoderma lucidum. Appl. Environ. Microbiol. $65,5307-5313$

Edwards, I. P., Zak, D. R., Kellner, H., Eisenlord, S. D., and Pregitzer, K. S. (2011). Simulated atmospheric $\mathrm{N}$ deposition alters fungal community composition and suppresses ligninolytic gene expression in a northern hardwood forest. PLoS ONE 6:e20421. doi: 10.1371/journal.pone.0020421

Eisenlord, S. D., Freedman, Z., Zak, D. R., Xue, K., He, Z. L., and Zhou, J. Z. (2013). Microbial mechanisms mediating increased sil C storage under elevated atmospheric N deposition. Appl. Environ. Microbiol. 79, 1191-1199. doi: 10.1128/AEM.03156-12

Eisenlord, S. D., and Zak, D. R. (2010). Simulated atmospheric nitrogen deposition alters actinobacterial community composition in forest soils. Soil Biol. Biochem. 74, 1157-1166. doi: 10.2136/sssaj2009.0240 
Falkowski, P. G., Fenchel, T., and Delong, E. F. (2008). The microbial engines that drive Earth's biogeochemical cycles. Science 320, 1034-1039. doi: $10.1126 /$ science. 1153213

Fawal, N., Li, Q., Savelli, B., Brette, M., Passaia, G., Fabre, M., et al. (2013). PeroxiBase: a database for large-scale evolutionary analysis of peroxidases. Nucleic Acids Res. 41, D441-D444. doi: 10.1093/nar/gks1083

Fierer, N., Lauber, C. L., Ramirez, K. S., Zaneveld, J., Bradford, M. A., and Knight, R. (2012). Comparative metagenomic, phylogenetic and physiological analyses of soil microbial communities across nitrogen gradients. ISME J. 6, 1007-1017. doi: 10.1038/ismej.2011.159

Fish, J. A., Chai, B. L., Wang, Q., Sun, Y. N., Brown, C. T., Tiedje, J. M., et al. (2013). FunGene: the functional gene pipeline and repository. Front. Microbiol. 4:291. doi: 10.3389/fmicb.2013.00291

Freedman, Z. B., Romanowicz, K. J., Upchurch, R. A., and Zak, D. R. (2015). Differential responses of total and active soil microbial communities to long-term experimental N deposition. Soil Biol. Biochem. 90, 275-282. doi: 10.1016/j.soilbio.2015.08.014

Freedman, Z. B., and Zak, D. R. (2015b). Atmospheric N deposition alters connectance, but not functional potential among saprotrophic bacterial communities. Mol. Ecol. 24, 3170-3180. doi: 10.1111/mec. 13224

Freedman, Z., Eisenlord, S. D., Zak, D. R., Xue, K., He, Z., and Zhou, J. (2013). Towards a molecular understanding of $\mathrm{N}$ cycling in northern hardwood forests under future rates of $\mathrm{N}$ deposition. Soil Biol. Biochem. 66, 130-138. doi: 10.1016/j.soilbio.2013.07.010

Freedman, Z., and Zak, D. R. (2014). Atmospheric N deposition increases bacterial laccase-like multicopper oxidases: implications for organic matter decay. Appl. Environ. Microbiol. 80, 4460-4468. doi: 10.1128/AEM.01224-14

Freedman, Z., and Zak, D. R. (2015a). Soil bacterial communities are shaped by temporal and environmental filtering: evidence from a longterm chronosequence. Environ. Microbiol. 17, 3208-3218. doi: 10.1111/14622920.12762

Frey, S. D., Knorr, M., Parrent, J. L., and Simpson, R. T. (2004). Chronic nitrogen enrichment affects the structure and function of the soil microbial community in temperate hardwood and pine forests. Forest Ecol. Manag. 196, 159-171. doi: 10.1016/j.foreco.2004.03.018

Galloway, J. N., Dentener, F. J., Capone, D. G., Boyer, E. W., Howarth, R. W., Seitzinger, S. P., et al. (2004). Nitrogen cycles: past, present, and future. Biogeochemistry 70, 153-226. doi: 10.1007/s10533-004-0370-0

Godden, B., Ball, A. S., Helvenstein, P., Mccarthy, A. J., and Penninckx, M. J. (1992). Towards elucidation of the lignin degradation pathway in Actinomycetes. J. Gen. Microbiol. 138, 2441-2448. doi: 10.1099/00221287-13811-2441

Gray, C. M., Monson, R. K., and Fierer, N. (2010). Emissions of volatile organic compounds during the decomposition of plant litter. J. Geophys. Res. Biogeosci. 115:G03015. doi: 10.1029/2010JG001291

Hesse, C. N., Mueller, R. C., Vuyisich, M., Gallegos-Graves, L. V., Gleasner, C. D., Zak, D. R., et al. (2015). Forest floor community metatranscriptomes identify fungal and bacterial responses to $\mathrm{N}$ deposition in two maple forests. Front. Microbiol. 6:337. doi: 10.3389/fmicb.2015.00337

Kirk, T. K., and Farrell, R. L. (1987). Enzymatic "combustion": the microbial degradation of lignin. Annu. Rev. Microbiol. 41, 465-505. doi: 10.1146/annurev.mi.41.100187.002341

Knight, R., Jansson, J., Field, D., Fierer, N., Desai, N., Fuhrman, J. A., et al. (2012). Unlocking the potential of metagenomics through replicated experimental design. Nat. Biotechnol. 30, 513-520. doi: 10.1038/nbt.2235

Lipson, D. A., and Schmidt, S. K. (2004). Seasonal changes in an alpine soil bacterial community in the Colorado Rocky Mountains. Appl. Environ. Microbiol. 70, 2867-2879. doi: 10.1128/AEM.70.5.2867-2879.2004

Liu, L. L., and Greaver, T. L. (2010). A global perspective on belowground carbon dynamics under nitrogen enrichment. Ecol. Lett. 13, 819-828. doi: 10.1111/j.1461-0248.2010.01482.x

Lombard, V., Ramulu, H. G., Drula, E., Coutinho, P. M., and Henrissat, B. (2014). The carbohydrate-active enzymes database (CAZy) in 2013. Nucleic Acids Res. 42, D490-D495. doi: 10.1093/nar/gkt1178

Maaroufi, N. I., Nordin, A., Hasselquist, N. J., Bach, L. H., Palmqvist, K., and Gundale, M. J. (2015). Anthropogenic nitrogen deposition enhances carbon sequestration in boreal soils. Glob. Chang. Biol. 21, 3169-3180. doi: $10.1111 /$ gcb. 12904

Magnani, F., Mencuccini, M., Borghetti, M., Berbigier, P., Berninger, F., Delzon, S., et al. (2007). The human footprint in the carbon cycle of temperate and boreal forests. Nature 447, 848-850. doi: 10.1038/nature05847

Martin, M. (2011). Cutadapt removes adapter sequences from high-throughput sequencing reads. EMBnet J. 17, 10-12. doi: 10.14806/ej.17.1.200

Meibom, K. L., Li, X. B., Nielsen, A. T., Wu, C. Y., Roseman, S., and Schoolnik, G. K. (2004). The Vibrio cholerae chitin utilization program. Proc. Natl. Acad. Sci. U.S.A. 101, 2524-2529. doi: 10.1073/pnas.0308707101

Meyer, F., Paarmann, D., D’souza, M., Olson, R., Glass, E. M., Kubal, M., et al. (2008). The metagenomics RAST server - a public resource for the automatic phylogenetic and functional analysis of metagenomes. BMC Bioinformatics 9:386. doi: 10.1186/1471-2105-9-386

Myrold, D. D., Zeglin, L. H., and Jansson, J. K. (2014). The potential of metagenomic approaches for understanding soil microbial processes. Soil Sci. Soc. Am. J. 78, 3-10. doi: 10.2136/sssaj2013.07.0287dgs

Navarrete, A. A., Tsai, S. M., Mendes, L. W., Faust, K., De Hollander, M., Cassman, N. A., et al. (2015). Soil microbiome responses to the short-term effects of Amazonian deforestation. Mol. Ecol. 24, 2433-2448. doi: 10.1111/mec.13172

Oburger, E., Leitner, D., Jones, D. L., Zygalakis, K. C., Schnepf, A., and Roose, T. (2011). Adsorption and desorption dynamics of citric acid anions in soil. Eur. J. Soil Sci. 62, 733-742. doi: 10.1111/j.1365-2389.2011.01384.x

Osono, T. (2007). Ecology of ligninolytic fungi associated with leaf litter decomposition. Ecol. Res. 22, 955-974. doi: 10.1007/s11284-007-0390-z

Overbeek, R., Olson, R., Pusch, G. D., Olsen, G. J., Davis, J. J., Disz, T., et al. (2014). The SEED and the rapid annotation of microbial genomes using Subsystems Technology (RAST). Nucleic Acids Res. 42, D206-D214. doi: $10.1093 /$ nar/gkt1226

Polaina, J., and Maccabe, A. P. (2007). Industrial Enzymes: Structure, Function, and Applications. Dordrecht: Springer.

Prather, M. J. (2003). Atmospheric science. An environmental experiment with $\mathrm{H}_{2}$ ? Science 302, 581-582. doi: 10.1126/science.1091060

Pregitzer, K. S., Zak, D. R., Burton, A. J., Ashby, J. A., and Macdonald, N. W. (2004). Chronic nitrate additions dramatically increase the export of carbon and nitrogen from northern hardwood ecosystems. Biogeochemistry 68, 179-197. doi: 10.1023/B:BIOG.0000025737.29546.fd

Prosser, J. I. (2010). Replicate or lie. Environ. Microbiol. 12, 1806-1810. doi: 10.1111/j.1462-2920.2010.02201.x

R Code Team (2013). R: A Language and Environment for Statistical Computing. Vienna: R Foundation for Statistical Computing.

Saiya-Cork, K. R., Sinsabaugh, R. L., and Zak, D. R. (2002). The effects of long term nitrogen deposition on extracellular enzyme activity in an Acer saccharum forest soil. Soil Biol. Biochem. 34, 1309-1315. doi: 10.1016/S00380717(02)00074-3

Sharpton, T. J. (2014). An introduction to the analysis of shotgun metagenomic data. Front. Plant Sci. 5:209. doi: 10.3389/fpls.2014.00209

Tatusova, T., Ciufo, S., Fedorov, B., O'neill, K., and Tolstoy, I. (2015). RefSeq microbial genomes database: new representation and annotation strategy (vol 42, pg 553, 2014). Nucleic Acids Res. 43, 3872-3872. doi: 10.1093/nar/gkv278

Torres, P. A., Abril, A. B., and Bucher, E. H. (2005). Microbial succession in litter decomposition in the semi-arid Chaco woodland. Soil Biol. Biochem. 37, 49-54. doi: 10.1016/j.soilbio.2004.04.042

Torseth, K., Aas, W., Breivik, K., Fjaeraa, A. M., Fiebig, M., Hjellbrekke, A. G., et al. (2012). Introduction to the European Monitoring and Evaluation Programme (EMEP) and observed atmospheric composition change during 1972-2009. Atmos. Chem. Phys. 12, 5447-5481. doi: 10.5194/acp-12-5447-2012

Uroz, S., Ioannidis, P., Lengelle, J., Cébron, A., Morin, E., Buee, M., et al. (2013). Functional assays and metagenomic analyses reveals differences between the microbial communities inhabiting the soil horizons of a Norway Spruce Plantation. PLoS ONE 8:e55929. doi: 10.1371/journal.pone.0055929

Voríšková, J., Brabcová, V., Cajthaml, T., and Baldrian, P. (2014). Seasonal dynamics of fungal communities in a temperate oak forest soil. New Phytol. 201, 269-278. doi: 10.1111/nph.12481

Waldrop, M. P., Zak, D. R., Sinsabaugh, R. L., Gallo, M., and Lauber, C. (2004). Nitrogen deposition modifies soil carbon storage through changes in microbial enzymatic activity. Ecol. Appl. 14, 1172-1177. doi: 10.1890/03-5120 
Wooley, J. C., Godzik, A., and Friedberg, I. (2010). A primer on metagenomics. PLoS Comput. Biol. 6:e1000667. doi: 10.1371/journal.pcbi. 1000667

Zak, D. R., Holmes, W. E., Burton, A. J., Pregitzer, K. S., and Talhelm, A. F. (2008). Simulated atmospheric $\mathrm{NO}_{3}^{-}$deposition increases soil organic matter by slowing decomposition. Ecol. Appl. 18, 2016-2027. doi: 10.1890/07-1743.1

Zhao, M. X., Xue, K., Wang, F., Liu, S. S., Bai, S. J., Sun, B., et al. (2014). Microbial mediation of biogeochemical cycles revealed by simulation of global changes with soil transplant and cropping. ISME J. 8, 2045-2055. doi: 10.1038/ismej.2014.46

Žifcáková, L., Vetrovský, T., Howe, A., and Baldrian, P. (2016). Microbial activity in forest soil reflects the changes in ecosystem properties between summer and winter. Environ. Microbiol. 18, 288-301. doi: 10.1111/1462-2920. 13026
Zimmerman, A. E., Martiny, A. C., and Allison, S. D. (2013). Microdiversity of extracellular enzyme genes among sequenced prokaryotic genomes. ISME J. 7, 1187-1199. doi: 10.1038/ismej.2012.176

Conflict of Interest Statement: The authors declare that the research was conducted in the absence of any commercial or financial relationships that could be construed as a potential conflict of interest.

Copyright (C) 2016 Freedman, Upchurch, Zak and Cline. This is an open-access article distributed under the terms of the Creative Commons Attribution License (CC BY).

The use, distribution or reproduction in other forums is permitted, provided the original author(s) or licensor are credited and that the original publication in this journal is cited, in accordance with accepted academic practice. No use, distribution or reproduction is permitted which does not comply with these terms. 